\title{
Role of Heme Oxygenase- 1(H0-1) and Endothelin-1 (ET-1) in Modulation of Cardioprotective Effect of Ischemic Postconditioning in Diabetic Rat Heart
}

\author{
Richa Rohilla ${ }^{1, *}$, Ahsas Goyal ${ }^{1}$, Vibhav Varshney ${ }^{1}$, Bhupesh Chander Semwal', \\ Harlokesh Narayan Yadav ${ }^{2}$
}

${ }^{1}$ Institute of Pharmaceutical Research, GLA University, Mathura, Uttar Pradesh, INDIA.

${ }^{2}$ All India Institute of Medical Sciences (AlIMS), Ansari Nagar East, New Delhi, INDIA.

\begin{abstract}
Background: We have recently reported that heme oxygenase-1 (HO-1) is involved in ischemic preconditioning-mediated cardioprotection by promoting nitric oxide (NO) release into diabetic rat heart (DRH). The upregulation of $\mathrm{HO}-1$ decreases the endothelin-1 (ET-1) production, which is a negative regulator of NO. In diabetes, the level of HO-1 is reduced while the level of ET-1 gets elevated. Thus, the present analysis was aimed to explore the concept of HO-1 and ET-1 in the abrogated cardioprotective role of ischemic post conditioning (IPOC) in the DRH. Materials and Methods: To explore the concept, a selective $\mathrm{HO}-1$ inducer hemin, $18 \mathrm{hrs}$ prior and a selective ETA receptor antagonist $\mathrm{BO}$ 123 , one week prior, were administered to $\mathrm{DRH}$ before isolation. $\mathrm{DRH}$ was removed and then mounted on Langendorff's apparatus, subjected to 10 min stabilization followed by $30 \mathrm{~min}$ ischemia. IPOC had been induced by four cycles of $5 \mathrm{~min}$ reperfusion along with $5 \mathrm{~min}$ ischemia followed by further $120 \mathrm{~min}$ of reperfusion. The extent of the infarct was measured and the coronary effluent was tested for the LDH, CK-MB and NO release. Results: In $\mathrm{DRH}$, cardioprotection mediated by the IPOC was significantly attenuated. Hemin and BQ-123 reinstated the impact of IPOC in DRH and also increased the release of NO. In BQ-123 pre-treated diabetic rat, the administration of hemin was unable to produce the additive cardioprotective effect of IPOC. Conclusion: Thus, it is suggested that hemin and $\mathrm{BQ}-123$ restore the attenuated cardioprotective effect of IPOC in the $\mathrm{DRH}$, which may be due to increased NO release.
\end{abstract}

Key words: Heme oxygenase-1, endothelin-1, Ischemic postconditioning, Diabetic rat heart, hemin, BQ-123.

\section{INTRODUCTION}

Ischemia/reperfusion (I/R) injury rousing with ischemia as well as restoration of blood flow to post-ischemic tissue, is accompanied with arrhythmias, myocardial apoptosis and necrosis resulting in increased mortality and morbidity. ${ }^{1-4}$ An ischemic post conditioning (IPOC) phenomenon may provide a useful approach to reduce the size of the infarction following short reperfusion/ ischemic episodes over a prolonged ischemic period. ${ }^{5,6}$ The IPOC persuades cardioprotection by stimulation of various endogenous molecules. ${ }^{7-11}$ Nevertheless, in many cases, the cardioprotective function of IPOC is attenuated..$^{12-15}$ One of the main threat of ischemic heart disease is diabetes mellitus.

Heme oxygenase-1 (HO-1) activates the oxidative breakdown of the cell heme for free iron, biliverdin, carbon monoxide (CO) and is also known as a rate-limiting enzyme. ${ }^{16}$ Besides heme catabolism, HO-1 also activates the eNOS (endothelial nitric oxide synthase), which leads to an increase in nitric oxide (NO) production, which is a well-known endogenous molecule to generate ischemic preconditioning (IPC) mediated cardioprotection. ${ }^{17}$ However, a
Submission Date: 28-01-2020; Revision Date: 30-03-2020; Accepted Date: 12-05-2020

DOI: 10.5530/ijper.54.3.119 Correspondence: Ms. Richa Rohilla M.Pharm Research Scholar, Department of Pharmacology, Institute of Pharmaceutical Research, GLA University Mathura-281406, Uttar Pradesh, INDIA.

Phone: +91 9997172129

E-mail: richa.rohilla10@ gmail.com

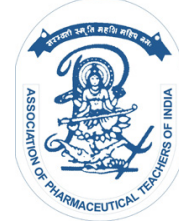

www.ijper.org 
decrease in HO-1 cardio specific expression has been reported to intensify whereas HO-1 up regulation results in cardioprotection against I/R injury. ${ }^{18-20}$ Furthermore, it has also been stated that the up regulation of HO-1 decreases the production of endothelin-1(ET-1), which is an effective vasoconstrictor peptide involved in various events, including vasoconstriction, stimulation of free radical formation and platelet activation. ${ }^{21,22}$ ET-1 has also been involved in the progress of vascular dysfunction and cardiovascular diseases as an important factor. ${ }^{23}$ Augmented plasma concentration of ET-1 has been stated in humans undergoing myocardial infarction. ${ }^{24}$ The production and the vasoconstrictor activity of ET-1 get up regulated during myocardial I/R injury. Moreover, NO is known to decrease the activity of ET-1. ${ }^{25}$

In diabetes, both the expression as well as the activity of HO-1 are reduced and the level of ET-1 gets elevated. ${ }^{19,26,27}$ Recently, we have demonstrated that hemin, an HO-1activator, restored the diminished IPC's cardioprotective upshot in the heart of diabetic rats. ${ }^{28}$ Therefore, to explore the role of HO-1 and ET-1 in the modulation of the IPOC's cardioprotective effect in DRH was the objective of this study.

\section{MATERIALS AND METHODS}

By the Institutional Animal Ethical Committee (IAEC), the experimental protocol of the present study has been accepted (GLAIPR/CPCSEA/IAEC/2014/P. $\mathrm{Col} / \mathrm{R} 05)$. As per the guidelines of the Indian National Science Academy, every experiment was carried out for the animal's use and care in scientific research. All of the animals had been given water ad libitum as well as regular chow diet (wheat flour 22.5\%, roasted Bengal gram powder $60 \%$, skimmed milk powder $5 \%$, casein $4 \%$, refined oil $4 \%$, salt mixture with starch $4 \%$ and vitamin and choline mixture $0.5 \%$ ) to survive.

\section{Drugs and chemicals}

A single dose of streptozotocin was used for the induction of diabetes mellitus. Hemin (HO-1 inducer; Sigma Aldrich [P] Ltd., Bangalore, India) was dissolved in $0.2 \mathrm{M} \mathrm{NaOH}$ and then injected to the rat. BQ-123 $\left(\mathrm{ET}_{\mathrm{A}}\right.$ receptor antagonist; Sigma Aldrich [P] Ltd., Bangalore, India) was dissolved in water for injection. In the study, every other reagent that was utilized was of the analytical grade and freshly prepared.

\section{Experimental design}

In Figure 1, the diagrammatic illustration of the experimental plan is depicted. In short, the Wistar rats had been arbitrarily grouped into eight groups containing six animals in each, called as Sham control, I/R control, IPOC control, IPOC in DRH, IPOC in $0.2 \mathrm{M} \mathrm{NaOH}$ (vehicle) pre-treated DRH, IPOC in hemin pre-treated DRH, IPOC in BQ-123 pre-treated DRH and IPOC in hemin and BQ-123 pre-treated DRH.

\begin{tabular}{|c|c|c|c|c|c|c|c|c|c|c|}
\hline \multicolumn{11}{|c|}{ Group 1: Sham Control $(n=6)$} \\
\hline $10 \cdot s$ & \multicolumn{10}{|c|}{$190 \mathrm{~K}-\mathrm{H}$} \\
\hline \multicolumn{11}{|c|}{ Group 2: I/R Control (n=6) } \\
\hline $10 \mathrm{~s}$ & $30 \mathrm{~T}$ & & & \multicolumn{7}{|c|}{$160 \mathrm{~K}-\mathrm{H}$} \\
\hline \multicolumn{11}{|c|}{ Group 3: Ischemic Postconditioning $(n=6)$} \\
\hline 10 's & $30 \mathrm{~T}$ & $5 \mathrm{r}$ & 5T & $5 \mathrm{R}$ & S'I & $5 \mathrm{R}$ & 5T & $5 \mathrm{R}$ & 5T & $120 \mathrm{~K}-\mathrm{H}$ \\
\hline \multicolumn{11}{|c|}{ Group 4: Ischemic Postconditioning in diabetic rat heart $(n=6)$} \\
\hline 10 's & $30 \mathrm{~T}$ & $5 \mathrm{R}$ & 5T & $5 \mathrm{R}$ & 5'I & $5 \mathrm{R}$ & 5T & $5 \mathrm{R}$ & 5I & $120 \mathrm{~K}-\mathrm{H}$ \\
\hline \multicolumn{11}{|c|}{ Group 5: Ischemic Postconditioning in vehicle $(0.2 \mathrm{M} \mathrm{NaOH})$ pretreated diabetic rat heart $(\mathrm{n}=6)$} \\
\hline 10 's & $30 \mathrm{~T}$ & $5 \mathrm{R}$ & 5T & $5 \mathrm{R}$ & S'I & $5 \mathrm{R}$ & 5T & 5R & 5I & $120 \mathrm{~K}-\mathrm{H}$ \\
\hline \multicolumn{11}{|c|}{ Group 6: Ischemic Postconditioning in Hemin $(4 \mathrm{mg} / \mathrm{kg})$ treated diabetic rat heart $(\mathrm{n}=6)$} \\
\hline 10 's & $30 \mathrm{~T}$ & $5 ' \mathrm{R}$ & $5 \mathrm{~T}$ & $5 \mathrm{R}$ & 5'T & $5 \mathrm{R}$ & $5 \mathrm{~T}$ & $5 \mathrm{R}$ & 5I & $120 \mathrm{~K}-\mathrm{H}$ \\
\hline \multicolumn{11}{|c|}{ Group 7: Ischemic Postconditioning in BQ-123(0.1mg/kg) treated diabetic rat heart $(\mathrm{n}=6)$} \\
\hline 10 's & $30 \mathrm{~T}$ & $5 ' \mathrm{R}$ & $5 \mathrm{~T}$ & $5 \mathrm{R}$ & 5'I & $5 \mathrm{R}$ & $5 \mathrm{I}$ & $5 \mathrm{R}$ & ST & $120 \mathrm{~K}$-H \\
\hline \multicolumn{11}{|c|}{ Group 8: Ischemic Postconditioning in Hemin $(4 \mathrm{mg} / \mathrm{kg})+$ BQ-123( $0.1 \mathrm{mg} / \mathrm{kg})$ treated diabetic rat heart $(\mathrm{n}=6)$} \\
\hline $10 ' \mathrm{~S}$ & $30 \mathrm{~T}$ & $5 ' \mathrm{R}$ & $5 \mathrm{~T}$ & $5 \mathrm{R}$ & S'I & $5 \mathrm{R}$ & $5 \mathrm{~T}$ & $5 \mathrm{R}$ & 5I & $120 \mathrm{~K}-\mathrm{H}$ \\
\hline
\end{tabular}

Figure 1: Diagrammatic representation of experimental protocol.

S: stabilization; P: perfusion; I: ischemia; R: reperfusion; K-H: Krebs-Hensleit solution. 
Experimental type- 2 diabetes was induced by singledose of streptozotocin. Isolated rat heart preparation for sham control, I/R control and IPOC control groups were followed by the previous publication of our lab. ${ }^{13}$ Briefly, global ischemia was produced for $30 \mathrm{~min}$ by blocking the inflow of Kreb's-Henseleit $\left(\mathrm{K}-\mathrm{H} ;\left(\mathrm{NaCl} 118 \mathrm{mM} ; \mathrm{KCl} 4.7 \mathrm{mM} ; \mathrm{CaCl}_{2} 2.5 \mathrm{mM}\right.\right.$; $\mathrm{MgSO}_{4} \cdot 7 \mathrm{H}_{2} \mathrm{O} 1.2 \mathrm{mM} ; \mathrm{KH}_{2} \mathrm{PO}_{4} 1.2 \mathrm{mM} ; \mathrm{C}_{6} \mathrm{H}_{12} \mathrm{O}_{6}$ $11 \mathrm{mM}$ ) buffer solution, which was followed by 160 min of reperfusion. IPOC was produced by 5 min of reperfusion followed by $5 \mathrm{~min}$ of ischemia by closing the inflow of K-H buffer solution. Four such episodes were employed. The same procedure of IPOC was followed for other group animals. Pre-treatment with $0.2 \mathrm{M} \mathrm{NaOH}$ (vehicle) and hemin (4 mg/kg, i.p.) was done before $18 \mathrm{hr}$ of isolation of heart form diabetic rat in groups 5 and 6, respectively. Further, in group 7, the pre-treatment with BQ-123 $(0.1 \mathrm{mg} / \mathrm{kg}$, i.p.) for a week was done before the heart isolation from the diabetic rat. Moreover, the combination of both hemin and BQ-123 was administered to group 8 animals. All animals were sacrificed by cervical dislocation and rats had been given heparin (500 IU/L, i.p.; Gland Pharma Ltd., Hyderabad, India)" twenty-minute prior for preventing coagulation. The heart was instantly excised as well as rapidly mounted on the apparatus of Langendorff. ${ }^{29}$ The coronary effluent was collected before $30 \mathrm{~min}$ of global ischemia and after that effluent was collected immediately and 5 min after the completion of four cycles of IPOC for the estimation of lactate dehydrogenase (LDH), creatinine kinase (CKMB) and nitrite.

\section{Induction of experimental diabetes}

Induction of experimental diabetes was done by singledose streptozotocin administration $\left(50 \mathrm{mg} / \mathrm{kg}\right.$, i.p.). ${ }^{30}$ Hyperglycaemia was confirmed using commercially accessible kit (Span diagnostic Ltd, Surat, India) spectrophotometrically at $505 \mathrm{~nm}$ after withdrawing

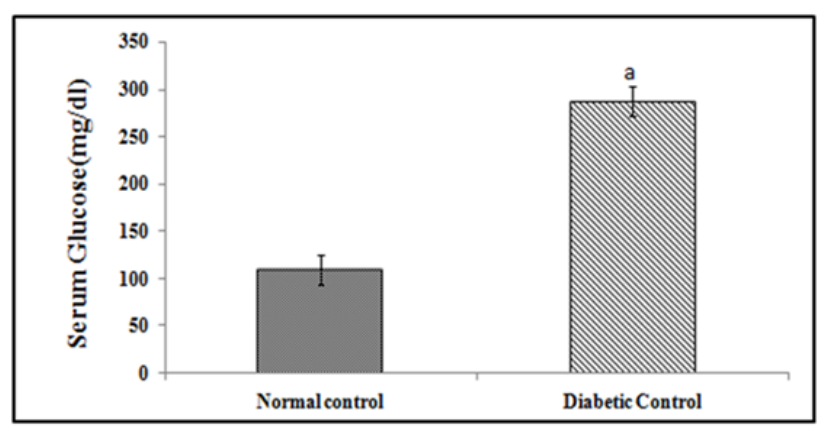

Figure 2: Effect of streptozotocin administration on serum glucose.

Value is expressed as mean \pm S.D. $a=P<0.05$ vs. control group. blood from rat orbital sinus. The amount of serum glucose $>200 \mathrm{mg} / \mathrm{dl}$ has been found hyperglycaemic.

\section{Assessment of myocardial injury and myocardial infarct size}

$\mathrm{LDH}$ and $\mathrm{CK}-\mathrm{MB}$ were assessed in the coronary effluent through the usage of the commercially available kit as a marker of myocardial injury (Coral clinical system, Goa, India). ${ }^{31,32}$ In international unit IU, values are stated per Liter (IU/L). Further, the myocardial infarct size was estimated through triphenyl tetrazolium chloride stain (TTC stain). ${ }^{31,33,34}$ Volume method was used for the measurement of infarct size. ${ }^{35}$ The percentage infarct area was calculated with the resulting given equation:

$\%$ Infarct area $=$ Infarct area $/$ Total area of slice $\times 100$.

\section{Nitrite Estimation}

Unlike NO, nitrite can be measured easily and nitrite concentrations can be used to infer levels of NO production. Nitrite release in coronary effluent was measured. ${ }^{36-38}$ Greiss reagent $0.5 \mathrm{ml}(1: 1$ solution of $1 \%$ sulphanilamide in 5\% phosphoric acid and $0.1 \%$ $\mathrm{N}$-(1-Naphthyl) ethylenediamine dihydrochloride in water) was added to $0.5 \mathrm{ml}$ of coronary effluent. The optical density at $550 \mathrm{~nm}$ was measured using a spectrophotometer. Nitrite concentration was calculated by comparison with spectrophotometer readings of a standard solution of sodium nitrite prepared in $\mathrm{K}-\mathrm{H}$ buffer. ${ }^{33}$ Results were expressed as micromoles per liter $(\mu \mathrm{M} / \mathrm{L})$.

\section{Statistical Analysis}

All values have been expressed as the mean \pm standard deviation (S.D). Using Microsoft Excel and GraphPad

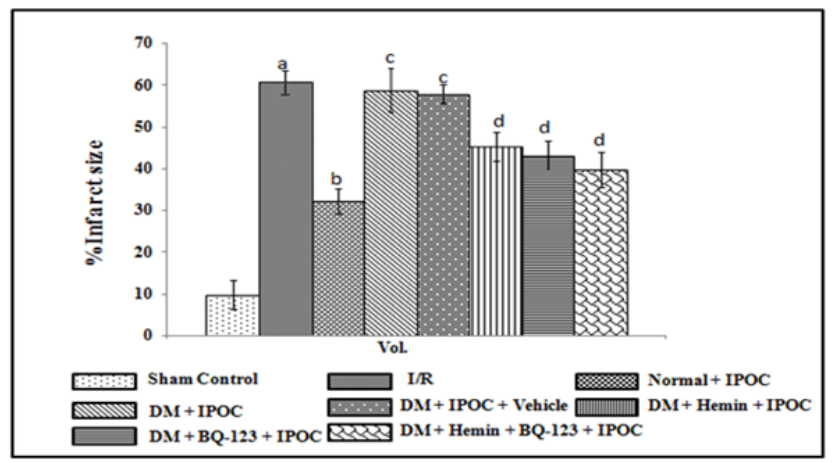

Figure 3: Effect of I/R on myocardial infarct size, effect of ischemic postconditioning on myocardial infarct size in normal and diabetic rat heart, effect of vehicle on myocardial infarct size in diabetic rat heart, effect of hemin and BQ-123 alone or in combination with each other on myocardial infarct size in diabetic rat heart.

$\mathrm{I} / \mathrm{R}$ denote ischemic reperfusion, IPOC denotes Ischemic post-conditioning, DM denotes diabetes mellitus. Values are expressed as mean \pm S.D. $a=P<0.05$ vs. sham control; $\mathrm{b}=P<0.05$ vs. I $\mathrm{R} ; \mathrm{c}=P<0.05$ vs. IPOC control; $\mathrm{d}=\mathrm{P}<0.05$ vs. IPOC in diabetic rat heart. 
prism 6.0, statistical analysis is performed. The data obtained from the various groups were statistically analyzed using one-way analysis of variance (ANOVA) followed by Student Newman-Keuls Post hoc test (infarct size and glucose estimation) and repeated measures of two-way ANOVA followed by Bonferroni Post hoc test (LDH, CK-MB and nitrite). P-value of less than 0.05 is measured as statistically substantial.

\section{RESULTS}

\section{Effect of streptozotocin on serum blood glucose}

In contrast to baseline values, the streptozotocin (50 $\mathrm{mg} / \mathrm{kg}$ i.p.) substantially increases blood glucose (Figure 2).

\section{Effect of IPOC and pharmacological intervention on myocardial infarct size}

Global ischemia for $30 \mathrm{~min}$. followed by $160 \mathrm{~min}$. of reperfusion significantly increased the myocardial infarct size as compared to sham control. Four cycles of $5 \mathrm{~min}$. of reperfusion and $5 \mathrm{~min}$. of ischemia were sufficient to markedly prevent the ischemia reperfusion-induced increase in infarct size in normal rat heart but not in DRH. Though, pre-treatment with hemin and BQ-123 alone or in combination significantly reestablished the IPOC tinduced reduction in myocardial infarct size in the DRH (Figure 3).

\section{Effect of IPOC and pharmacological intervention on myocardial injury (LDH and CK-MB)}

The release of $\mathrm{LDH}$ and $\mathrm{CK}-\mathrm{MB}$ increased significantly in comparison with sham after the global ischemia of

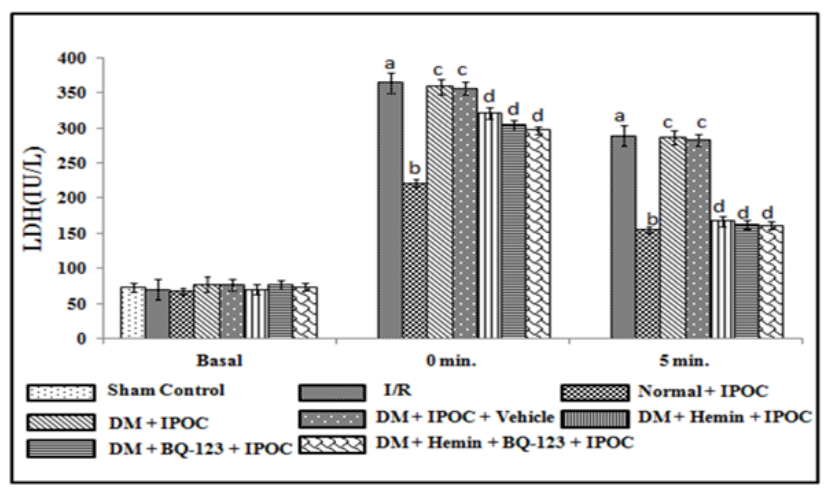

Figure 4: Effect of I/R on the release of LDH, effect of ischemic post conditioning on the release of LDH in normal and diabetic rat heart, effect of vehicle on the release of LDH in diabetic rat heart, effect of hemin and BQ-123 alone or in combination with each other on the release of LDH in diabetic rat heart.

$\mathrm{I} / \mathrm{R}$ denote ischemic reperfusion, IPOC denotes Ischemic post-conditioning, DM denotes diabetes mellitus. Values are expressed as mean \pm S.D. $a=P<0.05$ vs. sham control; $\mathrm{b}=P<0.05$ vs. I $/ \mathrm{R} ; \mathrm{c}=P<0.05$ vs. IPOC control; $\mathrm{d}=P<0.05$ vs. IPOC in diabetic rat heart.
$30 \mathrm{~min}$ followed by reperfusion of $160 \mathrm{~min}$. Four cycles of reperfusion of $5 \mathrm{~min}$ and of ischemia of $5 \mathrm{~min}$ were sufficient to prevent a substantial increase in $\mathrm{LDH}$, CK-MB release in normal rats but not in diabetic rats. However, pre-treatment with hemin and BQ-123 alone or in combination significantly re-established the IPOC induced reduction in the release of $\mathrm{LDH}$ and $\mathrm{CK}-\mathrm{MB}$ in the DRH (Figure 4,5).

\section{Effect of IPOC and pharmacological intervention on nitrite release}

Four occurrences of IPOC significantly raised the nitrite release in normal rat heart coronary effluent compared to the ischemic-reperfusion control group, but not in isolated DRH. Hemin and BQ-123 treatment alone or in combination, knowingly improved nitrite release in the DRH (Figure 6).

\section{DISCUSSION}

In this study, IPOC was adequate to significantly attenuate the $\mathrm{I} / \mathrm{R}$-induced increase in myocardial infarct size, $\mathrm{LDH}$ and $\mathrm{CK}-\mathrm{MB}$ release and reduced release of nitrite as coronary effluent in normal rat heart. These findings are as per our laboratory's previous published study. ${ }^{13}$

Heme-oxygenase 1 (HO-1) has been located in plasma membrane caveolae, where caveolin interacts. ${ }^{39}$ HO-1 triggers eNOS by the caveolin-eNOS complex disruption as well as promoting the release of nitric oxide, which is well known endogenous molecules that produce cardioprotection against I/ $\mathrm{R}$ injury. ${ }^{17,18,20,39,40}$ In addition, four cycles of $5 \mathrm{~min}$ of ischemia and

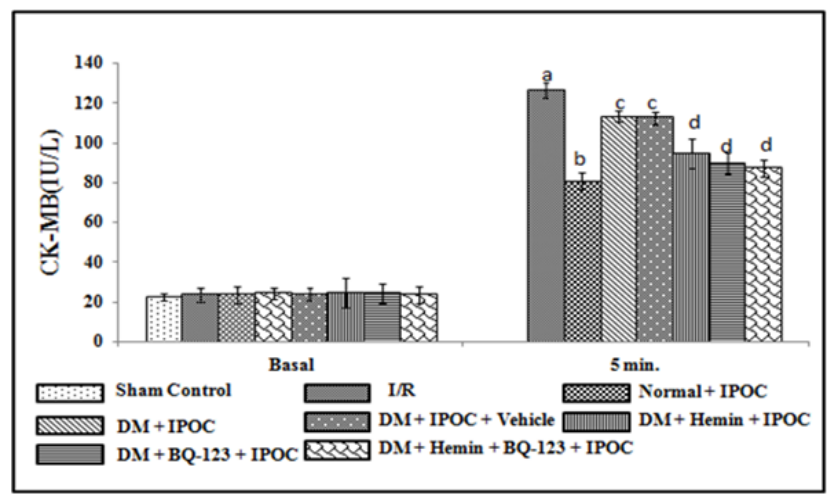

Figure 5: Effect of I/R on the release of CK-MB, effect of ischemic postconditioning on the release of CK-MB in normal and diabetic rat heart, effect of vehicle on the release of CK$M B$ in diabetic rat heart, effect of hemin and BQ-123 alone or in combination with each other on the release of CK-MB in diabetic rat heart.

I/R denote ischemic reperfusion, IPOC denotes Ischemic post-conditioning, DM denotes diabetes mellitus. Values are expressed as mean \pm S.D. $a=P<0.05$ vs. sham control; $\mathrm{b}=P<0.05$ vs. I $/ \mathrm{R} ; \mathrm{c}=P<0.05$ vs. IPOC control; $\mathrm{d}=P<0.05$ vs. IPOC in diabetic rat heart. 


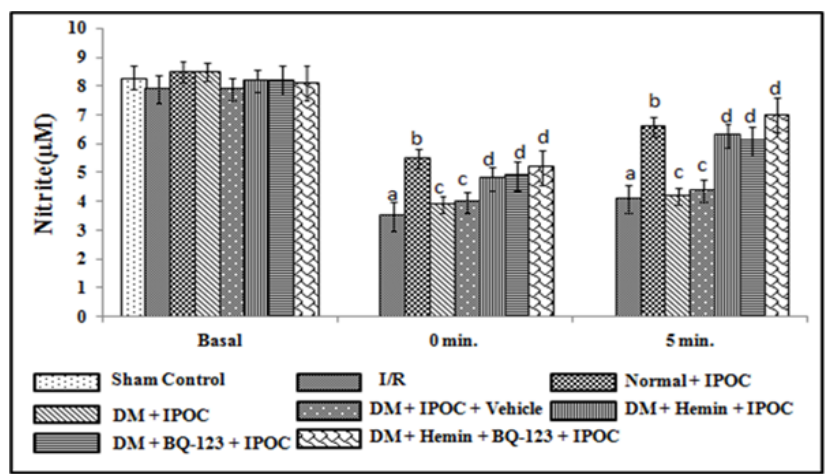

Figure 6: Effect of $\mathrm{I} / \mathrm{R}$ on the release of nitrite, effect of ischemic postconditioning on the release of nitrite in normal and diabetic rat heart, effect of vehicle on the release of nitrite in diabetic rat heart, effect of hemin and BQ-123 alone or in combination with each other on the release of nitrite in diabetic rat heart.

$\mathrm{I} / \mathrm{R}$ denote ischemic reperfusion, IPOC denotes Ischemic post-conditioning, DM denotes diabetes mellitus. Values are expressed as mean \pm S.D. a $=P<0.05$ vs. sham control; $\mathrm{b}=P<0.05$ vs. I/R; $\mathrm{c}=P<0.05$ vs. IPOC control; $\mathrm{d}=P<0.05$ vs. IPOC in diabetic rat heart.

5 min of reperfusion can also modulate caveolin microenvironment and promote signalling involving myocardium protection against injury caused by I/R. ${ }^{41}$ HO-1 expression and activity has been documented to be down-regulated in diabetic myocardium that subsequently down regulates the eNOS activity and exacerbates I/R injury. ${ }^{17,19,20 ~ “ I n ~ o u r ~ s t u d y, ~ I P O C ~ i n d u c e d ~}$ cardioprotection, along with the release of nitrite," was significantly reduced in DRH compared to normal rat heart. This may be due to reduced HO-1 expression along with the subsequent reduction in eNOS activity. Pre-treatment of diabetic rats with hemin, a specific HO-1 inducer, has significantly reinstated the IPOC's cardioprotective effect in the present study as well as raised the NO release in the heart of diabetic rat. It suggests that hemin treatment through activating HO-1 enhances the release of NO.

The powerful vasoconstrictor peptide endothelin-1 (ET$1)^{42}$ is enabled in different cell types by cardiovascular risk factors. In recent years there have been a large number of studies proposing that endothelin is involved in the mediation of heart ischemic-reperfusion damage. ${ }^{43}$ Though, production of ET-1 is downregulated by the stress of high shear as well as through the compounds that rise cyclic guanosine monophosphate's (cGMP) levels. ${ }^{44}$ Endothelin-1 acts as the natural counterpart of NO. Plasma ET-1 levels are elevated during endothelial dysfunction and diabetes mellitus. ${ }^{26,27}$ In our study, oneweek pre-treatment, with BQ-123, re-established the attenuated cardioprotective function of IPOC in the diabetic rat heart considerably relative to the untreated heart of a diabetic rat noted in terms of reduced infarct size and decrease in $\mathrm{LDH}$ and $\mathrm{CK}-\mathrm{MB}$ release and also increase in the release of NO. This finding supports that the infarct limiting effect of the BQ-123 is mediated through NO. The protective effect is in all probability NO-dependent, as it has been shown that inhibiting NOS abolishes the protective effect of antagonism to the ETA receptor. ${ }^{45}$

In addition, co-administration of BQ-123 for one week and hemin for $18 \mathrm{hr}$ before heart isolation in diabetic rats could not show any major cardioprotective effect of IPOC in comparison to both drug's individual administration in diabetic rat noted in terms of infarct size along with the $\mathrm{LDH}$ and $\mathrm{CK}-\mathrm{MB}$ release. After treatment with BQ-123 and hemin, the release of NO was increased compared with individual drugs. It may be proposed that once the release of $\mathrm{NO}$ achieves the threshold value by treatment with the individual drug, further increasing the release of NO is unable to produce additional cardioprotection.

\section{CONCLUSION}

As per the above discussion, it may be concluded that hemin and BQ-123 restore the attenuated cardioprotective effect of IPOC in DRH. This observed cardioprotection is due to an increase in the release of $\mathrm{NO}$ by hemin and BQ-123. Both HO-1 inducer and $\mathrm{ET}_{\mathrm{A}}$ receptor antagonist function in the same manner to produce IPOC mediated cardioprotection.

Our data indicate that individual administration with ischemic postconditioning of both drugs hemin and BQ-123 defends the myocardium from the injury of diabetes. Therefore, it is proposed that in diabetic patients undergoing cardiopulmonary bypass treatment with hemin and BQ-123 may be a valuable adjunctive for myocardial defense during open-heart surgery.

\section{LIMITATIONS OF THE PRESENT STUDY}

Ideally, Western blotting, which means to support the present study's findings, should have evaluated the proposed HO-1 and ET-1 levels.

\section{ACKNOWLEDGMENT AND STATEMENT OF CONTRIBUTION}

Vocabulary falls short of expressing my thankfulness to Shri Narayan Das Agrawal Ji (Chancellor, GLA University, Mathura, UP, India), Prof. Pradeep Mishra (Director, Institute of Pharmaceutical Research, GLA University), Prof. Meenakshi Bajpai (HOD, Institute of Pharmaceutical Research, GLA University) and Dr. Harlokesh Narayan Yadav, Associate Professor, GLA University, Mathura (Tenure- 2012-2015) (Currently 
working in AIIMS, New Delhi) for their worthy inspiration and continuous support throughout the research work. All authors contributed equally to this work. H.N.Y. developed the concept and designed the experiment. R.R performed an experiment in the laboratory. A.G., V.V and B.C.S carried out the analysis of results. R.R. prepared the manuscript.

\section{CONFLICT OF INTEREST}

The authors declare no conflict of interest.

\section{ABBREVIATIONS}

CPCSEA: Committee for the Purpose of Control and Supervision of Experiments on Animals; IAEC: Institutional Animal Ethics Committee; SD: Standard Deviation; I/R: Ischemia/reperfusion; IPOC: Ischemic postconditioning; NO: Nitric oxide; LDH: Lactate dehydrogenase; HO-1: Heme oxygenase-1; ET-1: Endothelin-1; CO: Carbon monoxide; IPC: Ischemic preconditioning; DRH: Diabetic rat heart.

\section{REFERENCES}

1. Murray CJ, Lopez AD. Global mortality, disability and the contribution of risk factor: global burden and disease study. Lancet. 1997;349(9063):1436-42.

2. Topol EJ, Califf RM, Vandormael M, Grines CL, George BS, Sanz ML, et al. A randomized trial of late reperfusion therapy for acute myocardial infarction. thrombolysis and angioplasty in myocardial infarction-6 study group. Circulation. 1992;85(6):2090-9.

3. Baxter GF, Ebrahim Z. Role of bradykinin in preconditioning and protection of the ischaemic myocardium. Br J Pharmacol. 2002;135(4):843-54.

4. Piper $\mathrm{HM}$, Abdallah $\mathrm{Y}$, Schafer $\mathrm{C}$. The first minutes of reperfusion: A window of opportunity for cardioprotection. Cardiovasc Res. 2004;61(3):365-71.

5. Vinten-Johansen J, Yellon DM, Opie LH. Postconditioning. a simple, clinically applicable procedure to improve revascularization in acute myocardial infarction. Circulation. 2005;112:2085-8.

6. Zhao ZQ, Corvera JS, Halkos ME, Kerendi F, Wang NP, Guyton RA, et al. Inhibition of myocardial injury by ischemic postconditioning during reperfusion: Comparison with ischemic preconditioning. Am J Physiol Heart Circ Physiol. 2003;285(2):H579-88.

7. Philipp S, Yang XM, Cui L, Davis AM, Downey JM, Cohen MV. Postconditioning protects rabbit hearts through a protein kinase $\mathrm{C}$-adenosine $\mathrm{A} 2 \mathrm{~b}$ receptor cascade. Cardiovasc Res. 2006;70(2):308-14.

8. Penna C, Mancardi D, Rastaldo R, Losano G, Pagliaro P. Intermittent activation of bradykinin $B(2)$ receptors and mitochondrial KATP channels trigger cardiac postconditioning through redox signaling. Cardiovasc Res. 2007;75(1):168-77.

9. Li D, Li NS, Chen QQ, Guo R, Xu PS, Deng HW, et al. Calcitonin gene-related peptide-mediated cardioprotection of postconditioning in isolated rat hearts. Regul Pept. 2008;147(1-3):4-8.

10. Hausenloy DJ, Tsang A, Yellon DM. The reperfusion injury salvage kinase pathway: A common target for both ischemic preconditioning and postconditioning. Trends Cardiovasc Med. 2005;15(2):69-75.

11. Selzner N, Boehnert M, Selzner M. Preconditioning, postconditioning and remote conditioning in solid organ transplantation: Basic mechanisms and translational applications. Transplantation Rev. 2012;26(2):115-24.

12. Ferdinandy $P$, Schulz R, Baxter GF. Interaction of cardiovascular risk factors with myocardial ischemia/reperfusion injury, preconditioning and postconditioning. Pharmacol Rev. 2007;59(4):418-58.
13. Varshney V, Goyal A, Gupta JK, Yadav HN. Role of erythropoietin in ischemic postconditioning induced cardioprotection in hyperlipidemic rat heart. Indian College of Cardiology. 2017;7(2):72-7.

14. Zhao H, Wang Y, Wu Y, Li X, Yang G, Ma X, et al. Hyperlipidemia does not prevent the cardioprotection by postconditioning against myocardial ischemia/reperfusion injury and the involvement of hypoxia inducible factor1alpha upregulation. Acta Biochim Biophys Sin. 2009;41(9):745-53.

15. Yin X, Zheng Y, Zhai X, Zhao X, Cai Lu. Diabetic inhibition of preconditioningand postconditioning-mediated myocardial protection against ischemia/ reperfusion injury. Exp Diabetes Res. 2012;9. Article ID 198048.

16. Ryter SW, Alam J, Choi AM. Heme oxygenase-1/carbon monoxide: From basic science to therapeutic applications. Physiol Rev. 2006;86(2):583-650.

17. Penumathsa SV, Koneru S, Samuel SM, Zhan L, Menon VP, Maulik N. Red wine polyphenol resveratrol regulates heme oxygenase-1 conversely for the disruption of Caveolin-1/eNOS platform and improves left ventricular function in ischemic hypercholesterolemic myocardium. FASEB J. 2008;22:1130.

18. Penumathsa SV, Koneru S, Samuel SM, Maulik G, Bagchi D, Yet SF, et al. Strategic targets to induce neovascularization by resveratrol in hypercholesterolemic rat myocardium: role of caveolin-1, endothelial nitric oxide synthase, hemeoxygenase-1 and vascular endothelial growth factor. Free Radic Biol Med. 2008a;45(7):1027-34.

19. Li M, Peterson S, Husney D, Inaba M, Guo K, Terada E, et al. Interdiction of the diabetic state in NOD mice by sustained induction of heme oxygenase: Possible role of carbon monoxide and bilirubin. Antioxid Redox Signal. 2007;9(7):855-63.

20. Thirunavukkarasu M, Penumathsa SV, Koneru S, Juhasz B, Zhan L, Otani $\mathrm{H}$, et al. Resveratrol alleviates cardiac dysfunction in streptozotocin-induced diabetes: role of nitric oxide, thioredoxin and heme oxygenase. Free Radic Biol Med. 2007;43(5):720-9.

21. Morita T, Kourembanas S. Endothelial Cell Expression of vasoconstrictors and growth factors is regulated by smooth muscle cell-derived carbon monoxide. J Clin Invest. 1995;96(6):2676-82.

22. Yanagisawa M, Kurihara H, Kimura S, Tomobe $\mathrm{Y}$, Kobayashi M, Mitsui $\mathrm{Y}$, et al. A novel potent vasoconstrictor peptide produced by vascular endothelial cells. Nature. 1988;332(6163):411-5.

23. Ergul A. Endothelin-1 and diabetic complications: Focus on the vasculature. Pharmacol Res. 2011;63(6):477-82.

24. Stewart DJ, Kubac G, Costello KB, Cernacek P. Increased plasma concentrations of endothelin- 1 in the early hours of acute myocardial infarction. J Am Coll Cardiol. 1991;18:38-43.

25. Bohm F, Pernow J. The importance of endothelin-1 for vascular dysfunction in cardiovascular disease. Cardiovasc Res. 2007;76(1):8-18.

26. Cameron NE, Dines KC, Cotter MA. The potential contribution of endothelin-1 to neurovascular abnormalities in streptozotocin-diabetic rats. Diabetologia. 1994;37(12):1209-15.

27. Kanie N, Kamata K. Effect of chronic administration of the novel endothelin antagonist J-104132 on endothelial dysfunction in streptozotocin-induced diabetic rat. Br J Pharmacol. 2002;135(8):1935-42.

28. Gupta I, Goyal A, Singh NK, Yadav HN, Sharma PL. Hemin, a heme oxygenase-1 inducer, restore the attenuated cardioprotective effect of ischemic preconditioning in isolated diabetic rat heart. Hum Exp Toxicol. 2017;36(8):867-75.

29. Lagendorff $O$. Unter such ungenamuberle bender sauge thier herzen. $P$ flugers Arch Ges Physiol Mensch Tiere. 1895;61:291-332.

30. Ozansoy G, Akin FB. Effects of gemfibrozil treatment on vascular reactivity of streptozotocin-diabetic rat aorta. J Pharma Pharmacol. 2004;56(2):241-6.

31. Yadav HN, Singh M, Sharma PL. Involvement of GSK-3 $\beta$ in attenuation of cardioprotective effect of ischemic preconditioning in diabetic rat heart. Mol Cell Biochem. 2010;343(1-2):75-81.

32. Skrzypiec-Spring M, Grotthus B, Szelag A, Schulz R. Isolated heart perfusion according to Langendorff-Still viable in the new millennium. J Pharmacol Toxicol Methods. 2007;55(2):113-26.

33. Ajmani P, Yadav HN, Singh M, Sharma PL. Possible involvement of caveolin in attenuation of cardioprotective effect of ischemic preconditioning in diabetic rat heart. BMC Cardiovascular Disord. 2011;11(1):1-10.

34. Fishbein MC, Meerbaum S, Rit J, Lando U, Kanmatsuse K, Mercier JC, et al. Early phase of acute myocardial infarct size quantification: Validation of the triphenyl tetrazolium chloride tissue enzyme staining technique. Am Heart J. 1981;101(5):593-600. 

infarct size with desferrioxamine: Possible role of oxygen free redicals in its ameliorative effect. Mol Cell Biochem. 1992;113(1):71-6.

36. Marletta MA, Yoon PS, lyengar R, Leaf CD, Wishnok JS. Macrophage oxidation of L-arginine to nitrite and nitrate: Nitric oxide is an intermediate. Biochemistry. 1988;27(24):8706-11.

37. Szabo C, Thiemermann C, Vane JR. Dihydropyridine antagonists and agonists modulators of calcium channels inhibit the induction of nitric oxide synthase by endotoxin in cultured macrophages. Biochem Biophys Res Commun. 1993;196(2):825-30.

38. Szabo C, Wu CC, Mitchell JA, Gross SS, Thiemermann C, Vane JR. Plateletactivating factor contributes to the induction of nitric oxide synthase by bacterial lipopolysaccharide. Circ Res. 1993;73(6):991-9.

39. Kim HP, Wang X, Galbiati F, Ryter SW, Choi AM. Caveolae compartmentalization of heme oxygenase-1 in endothelial cells. FASEB J. 2004;18(10):1080-9.
40. Goyal A, Semwal BC, Yadav HN. Abrogated cardioprotective effect of ischemic preconditioning in ovariectomized rat heart. Hum Exp Toxicol. 2016;35(6):644-53.

41. Koneru S, Penumathsa SV, Thirunavukkarasu M, Samuel SM, Zhan L, Han $Z$, et al. Redox regulation of ischemic preconditioning is mediated by the differential activation of caveolins and their association with eNOS and glut-4. Am J Physiol Heart Cir Physiol. 2007;292(5):H2060-72.

42. Yanagisawa $\mathrm{M}$, Kurihara $\mathrm{H}$, Kimura $\mathrm{S}$, Tomobe $\mathrm{Y}$, Kobayashi M, Mitsui $\mathrm{Y}$, et al. A novel potent vasoconstrictor peptide produced by vascular endothelial cells. Nature. 1988;332(6163):411-5.

43. Bugge E, Ytrehus K. Endothelin-1 can reduce infarct size through protein kinase $\mathrm{C}$ and KATP, channels in the isolated rat heart. Cardiovasc Res. 1996;32(5):920-9.

44. Gray GA. Molecular biology and pharmacology of endothelins. In: Generartion of endothelin, Landes. 1995;13-32.

45. Gourine AV, Gonon AT, Pernow J. Involvement of nitric oxide in cardioprotective effect of endothelin receptor antagonist during ischemia-reperfusion. Am J Physiol Heart Circ Physiol. 2001;280(3):H1105-12.

\section{PICTORIAL ABSTRACT}

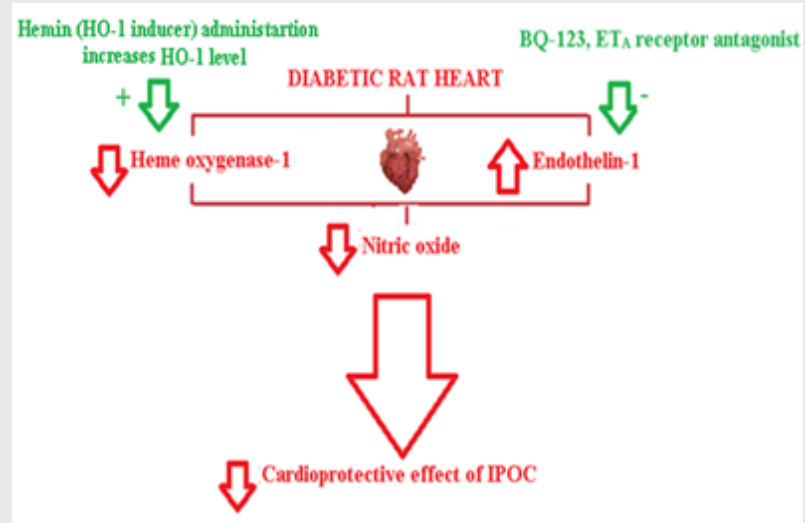

\section{SUMMARY}

- Upregulation of HO-1 decreases the endothelin-1 (ET-1) production which is a negative regulator of NO.

- In diabetes condition, level of HO-1 is reduced while the level of ET-1 gets elevated.

- In diabetic rat heart, cardioprotection mediated by the IPOC was significantly attenuated.

- In our study, hemin administration, a selective HO-1 inducer and BQ-123, a selective ETA receptor antagonist, restored the attenuated cardioprotective impact of IPOC in diabetic rats and also increased the release of NO.

- Therefore, it is proposed that in diabetic patients undergoing cardiopulmonary bypass treatment with hemin and BQ-123 may be a beneficial adjunctive for myocardial defence during open heart surgery. 


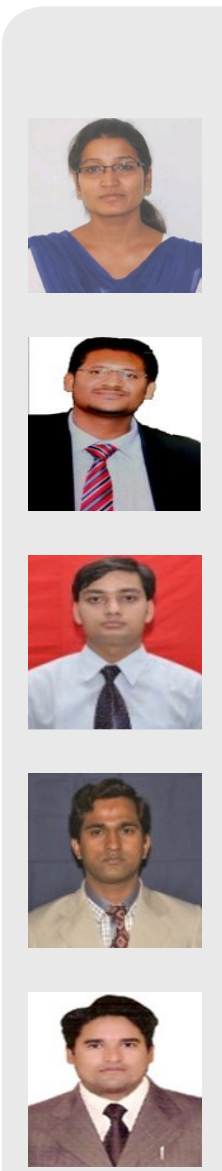

\section{About Authors}

Ms. Richa Rohilla is Research Scholar in Department of Pharmacology, Institute of Pharmaceutical Research, GLA University, Mathura.

Mr. Ahsas Goyal is currently Assistant Professor in Institute of Pharmaceutical Research, GLA University, Mathura, has been actively engaged in pharmacology \& toxicology research and teaching for last 6 years. He has been resourceful contributor of research papers in journals of national and international repute.

Mr. Vibhav Varshney is currently Lecturer in Institute of Pharmaceutical Research, GLA University, Mathura, has been actively engaged in pharmacology \& toxicology research and teaching.

Mr. Bhupesh Chander Semwal is currently Assistant Professor in Institute of Pharmaceutical Research, GLA University, Mathura, has been actively engaged in pharmacology \& toxicology research and teaching for last 10 years.

Dr. Harlokesh Narayan Yadav is currently Associate Professor in All India Institute of Medical Sciences (AlIMS), New Delhi, has been actively engaged in cardiovascular research and teaching for the last 10 years. He has been resourceful contributor of 20 research papers in journals of national and international repute. He was facilitated by various prestigious awards like Gold medal for Dr. Manjeet Singh Award (2010) for best research work in Molecular Pharmacology. Gold medal for N.N. Datta Prize (2010) for best published research paper in Indian Journal of Pharmacology (2009-2010), by Indian Pharmacological society.

Cite this article: Rohilla R, Goyal A, Varshney V, Semwal BC, Yadav HN. Role of Heme Oxygenase- 1(HO-1) and Endothelin-1 (ET-1) in Modulation of Cardioprotective effect of Ischemic Postconditioning in Diabetic Rat Heart. Indian J of Pharmaceutical Education and Research. 2020;54(3):690-7. 